\title{
Podosome-type adhesions and focal adhesions, so alike yet so different
}

Block Marc R. , Badowski Cedric, Millon-Fremillon Angelique , Bouvard Daniel , Bouin Anne-Pascale , Faurobert Eva , Gerber-Scokaert Delphine , Planus Emmanuelle , Albiges-Rizo Corinne *

DySAD, Dynamique des systèmes d'adhérence et différenciation CNRS : ERL3148, INSERM : U823, FR

* Correspondence should be adressed to: Corinne Albiges-Rizo <corinne.albiges-rizo@ujf-grenoble.fr>

\begin{abstract}
Cell-matrix adhesions are essential for cell migration, tissue organization, and differentiation, therefore playing central roles in embryonic development, remodeling and homeostasis of tissue and organs. Matrix adhesion dependent signals cooperate with other pathways to regulate biological functions such as cell survival, cell proliferation, wound healing and tumorigenesis. Cell migration and invasion are integrated processes requiring the continuous, coordinated assembly and disassembly of integrin-mediated adhesions. An understanding of how integrins regulate cell migration and invasiveness through the dynamic regulation of adhesions is fundamental to both physiological and pathological situations. A variety of cell-matrix adhesions has been identified, namely, focal complexes, focal adhesions, fibrillar adhesions, podosomes and invadopodia (podosome type adhesions). These adhesion sites contain integrin clusters able to develop specialized structures which are different in their architecture and dynamics although they share almost the same proteins. Here we compare recent advances and developments in the organization and dynamics of focal adhesions and podosome type adhesions, in order to understand how such subcellular sites so close in their composition can be structurally and functionally so different. The underlying question is how their respective physiological or pathological roles are related to their distinct organization.
\end{abstract}

MESH Keywords Actins ; metabolism ; Animals ; Cell Adhesion ; Cell Movement ; physiology ; Cell-Matrix Junctions ; metabolism ; Extracellular Matrix ; metabolism ; Focal Adhesions ; metabolism ; Humans ; Integrins ; metabolism ; Models, Biological

Author Keywords Podosomes ; invadopodia ; invasion ; cancer ; osteoporosis

\section{Introduction}

Many distinct types of adhesions between cells and the extracellular matrix have been described: focal complexes, focal adhesions, fibrillar adhesions, podosomes and invadopodia (Fig. 1). These cell-extracellular matrix interactions are all mediated through different specialized subcellular sites that all contain specific adhesion receptors named integrins, cytoskeletal elements, and a wide variety of interconnecting adaptor proteins and signaling proteins. Some of those proteins can be specifically expressed at differentiation states such as RhoU/Wrch1 which is induced during the differentiation of macrophages into osteoclasts (Brazier et al., 2006). Although adhesive structures share almost the same proteins (Table 1), major structural differences are observed: podosomes contain a ring of adhesive molecules centered on an actin column and their general orientation is perpendicular to the substrate and the plasma membrane. This contrasts with the elongated structure of focal adhesions with a tangential orientation with respect to extracellular matrix (Fig. 1). Dynamics and tension associated to both structures are also different: podosome type adhesions (PTA) associated with podosomes and invadopodia being more dynamic and instable as compared to focal adhesions. In all cases, alteration of their dynamics results in modifications of cell differentiation and migration (Vicente-Manzanares et al., 2005; Bouvard et al., 2007). These distinct properties suggest specific functions: the most commonly admitted idea is that podosomes and invadopodia could be involved in matrix degradation and invasion, whereas focal adhesions are rather associated with matrix remodeling such as fibronectin fibrillogenesis (Larsen et al., 2006; Linder, 2007).

Due to their involvement in physiological and pathological situations, cell-matrix adhesions are now receiving widespread attention. Indeed, podosomes and invadopodia could be involved in physiological events such as monocyte extravasation and tissue transmigration ( Carman et al., 2007) or in pathological conditions such as atheroma (Moreau et al., 2003), osteoporosis or osteopetrosis. Cancer cells are also able to exploit cell-matrix adhesions such as focal adhesions and invadopodia (Paszek et al., 2005; Marx, 2006). In the past few years, mutations on proteins located in focal adhesions and/or podosomes allowed to characterize some pathologies: for instance, WASP is associated with Wiskott-Aldrich syndrome causing a severe immunodeficiency, Kindlin is associated with Kindler syndrome (Siegel et al., 2003) causing skin blistering, skin atrophy, photosensitivity, carcinogenesis, and palladin is causing familial pancreatic cancer ( Pogue-Geile et al., 2006). Nevertheless, the precise relationship between these pathologies and adhesion is still unclear.

Here, we will focus on the architecture, dynamics and tension of focal adhesions and podosome type adhesions (podosomes and invadopodia). The aim of this review is to point out the most convergent and divergent characteristics of these specific cell-matrix structures.

\section{Architecture and signaling pathways of cell matrix contacts}


Focal adhesions are the best characterized type of such structures. They were initially described about 30 years ago by interference-reflection microscopy and electron microscopy (Abercrombie et al., 1971). Although many investigators have thought that focal adhesions were artifactual structures only found in cells cultured on rigid surfaces, such structures have been described in vivo at cell-matrix junctions (Fuchs et al., 1997; Cukierman et al., 2001). In cell culture, a family of focal adhesion related structures has been identified and named focal complexes, focal adhesions and fibrillar adhesions, respectively (Zamir and Geiger, 2001). Focal complexes are 0.5-1 $\mu \mathrm{m}$ dot-like contacts localized along the lamellipodia. These structures are not connected to stress fibers although they have been shown to be linked to the actin network. Moreover, they do not contain Zyxin suggesting that they are subjected to moderate mechanical tensions (see next section). Focal complexes mature into focal adhesions (Fig. 1A), the elongated 3-10 $\mu \mathrm{m}$ structures associated with stress fibers. Those structures give rise to fibrillar adhesions enriched in tensin and involved in fibronectin fibrillogenesis (Fig. 1A) (Katz et al., 2000). Up to 90 components have been reported to physically reside within these adhesions while 66 temporary players interact with the resident adhesion constituents and affect their activity and fate (Fig. 1B) (Zaidel-Bar et al., 2007). Focal adhesions are mostly composed of $\beta_{1}$ and $\beta_{3}$ integrins. Moreover, some structural proteins found in focal adhesions and devoid of any catalytic activity are however involved in dynamics of the structure: for instance, talin controls integrin activation, vinculin is selectively activated by changes in head-tail interactions regulated by binding to talin (Izard et al., 2004; Chen et al., 2005; Humphries et al., 2007), a-actinin forms a signaling complex with the Abl/Arg kinase adapter ArgBP2 (Ronty et al., 2005) and paxillin integrates diverse signals from tyrosine kinases and Rho family GTPases (Brown and Turner, 2004). Another complex composed of integrin-linked kinase (ILK), PINCH and parvin also functions as a signaling platform for integrins (Legate et al., 2006; Boulter et al., 2006). Additionally, focal adhesions contain a rich diversity of enzymatically active proteins. Indeed, tyrosine phosphorylation is one of the key signaling events occurring at focal adhesions (Kirchner et al., 2003). Two of the major protein tyrosine kinases found in focal adhesion are Src and focal adhesion kinase (FAK). The latter undergoes autophosphorylation that generates a docking site for Src allowing further tyrosine phosphorylations on FAK and recruitment sites for potential substrates such as p130Cas or paxillin (Schaller et al., 1994; Frame et al., 2002). Other tyrosine kinases such as Abl, Csk and Pyk2 and ser/thr kinases such as ILK, PAK, and PKC are also found in focal adhesions.

It is note worthy that most of data are issued from studies done on cells plated on 2D matrices and cell signalling seems to be different when comparing cells in 3D microenvironment to 2D matrices. In particular, adhesion in 3D microenvironment has to be found to be dependent solely on the $\alpha_{5} \beta_{1}$ integrin whereas the attachment of fibroblasts to $2 \mathrm{D}$ fibronectin is dependent on both $\alpha_{5} \beta_{1}$ and $\alpha_{v} \beta_{3}$ integrins ( Cukierman et al., 2001; Green and Yamada, 2007).

\section{Perpendicular cell matrix contacts: podosome type adhesions}

Migratory and invasive cells exhibit another type of integrin-mediated adhesion complexes called PTA, namely podosome type adhesions (Linder, 2007). Depending on their life time and structure, they have been referred to as podosomes or invadopodia. Podosomes have been observed in cells of the monocytic lineage such as osteoclasts, macrophages and dendritic cells whereas invadopodia have been identified in Src-transformed fibroblasts and carcinoma cells (Linder and Aepfelbacher, 2003). Podosomes and invadopodia architecture is defined by an actin-rich core (Marchisio et al., 1984; Pfaff and Jurdic, 2001; Baldassarre et al., 2006), where proteins involved in actin nucleation such as WASP (Linder et al., 1999; Mizutani et al., 2002), Arp2/3 and cortactin (Bowden et al., 1999; Linder et al., 2000; Pfaff and Jurdic, 2001; Artym et al., 2006; Bowden et al., 2006; Luxenburg et al., 2006; Tehrani et al., 2006; Webb et al., 2007) have been identified (Fig. 1C, D). Podosome core is surrounded by a ring structure composed of integrin receptors including mostly $\beta_{2}$ and $\beta_{3}$ while $\beta$ 1 integrins are generally excluded (Gaidano et al., 1990). Integrin-associated protein also found in focal adhesions such as talin and paxillin (Bowden et al., 1999; Pfaff and Jurdic, 2001; Buccione et al., 2004) are also found around the actin core. This organization is not so well defined for invadopodia where the adhesive molecules may be mixed within the actin core. Invadopodia of Src-transformed cells were shown to self organize into podosomes ring named rosettes similarly to what was observed for podosomes in osteoclasts (Destaing et al., 2003) and endothelial cells (Moreau et al., 2003). Although FAK is expressed in many cells able to develop podosomes or invadopodia, Pyk2 appears to be the predominant mediator of integrin $\alpha_{v} \beta_{3}$ signaling events in the hematopoietic lineage that influence podosome assembly in osteoclast (Wang et al., 2003) or macrophage behavior (Okigaki et al., 2003). However Pyk2 has also been observed in focal adhesion (Du et al., 2001). Strikingly, Pyk2 is activated following increases in cytosolic free $\mathrm{Ca}^{2+}$, (Lev et al., 1995; Rucci et al., 2005) due to voltage dependent channels (Miyauchi et al., 1990). Pyk2 autophosphorylates on Tyr 402, creating a Src-homology-2 (SH2) binding site that recruits Src family kinases (SFK), which phosphorylate other tyrosine residues of Pyk2 and associated proteins (Dikic et al., 1996; Park et al., 2004). Interactions between the activated Pyk2-Src module and proteins such as the Grb2-Sos complex, p130Cas, paxillin and Graf regulate multiple intracellular signaling pathways reviewed in (Avraham et al., 2000). Binding of $\alpha_{v} \beta_{3}$ integrin induces the formation of a Pyk2/Src/Cbl complex in which $\mathrm{Cbl}$, an E3 ubiquitin ligase, is a key regulator of Src kinase activity, and of cell adhesion and osteoclast migration (Sanjay et al., 2001).

\section{Interplay between focal adhesions, podosome type adhesions and cell contractility}


During cell migration, adhesions at the front of the cell must be strong enough to withstand contractile forces generated by the cell front while adhesions at the rear must be weak enough to allow the cell to detach from its substrate. This means that asymmetry in the strength of adhesions at the cell front and rear is likely important for efficient cell migration. Several parameters may contribute to the strength of adhesion between a cell and its environment including ligand surface density, number of adhesion receptors, affinity of integrins towards their respective ligands, strength of receptor linkages, and organization of receptors on the cell surface (Huttenlocher et al., 1996; Palecek et al., 1998; Gallant et al., 2005; Gupton and Waterman-Storer, 2006).

During cell attachment and spreading, initial adhesions evolve into small focal complexes that mature into focal adhesions connected to stress fibers. During this initial process, auto-assembly requires the application of a force on integrin receptors up to $2 \mathrm{pN}$. Formation of focal complexes results in a reinforcement of this mechanical link to $5 \mathrm{nN}$ (Galbraith et al., 2002; Giannone et al., 2003; Buruinsma, 2005 ). This stage is under the control of the small GTPase Rac1 (Rottner et al., 1999). Mature focal adhesions are adhesive structures of larger size and relative immobility with respect to the substrate. Their assembly is stimulated by the small GTPase RhoA (Ridley and Hall, 1992 ), and is mediated primarily via two of its immediate downstream effectors, RhoKinase and mDia (Kimura et al., 1996; Watanabe et al., 1999). RhoKinase stimulates myosin II-dependent contractility in smooth muscle and non-muscle cells by inactivating myosin light chain phosphatase (Katoh et al., 2001), whereas mDia is implicated in the regulation of actin polymerisation and the initiation of parallel arrays of actin filaments, probably through the recruitment of newly formed actin filaments to stress fibers (Burridge and Chrzanowska-Wodnicka, 1996; Rottner et al., 1999). Myosin II exerts on focal adhesion a force of $5.2 \mathrm{nN} / \mu \mathrm{m}^{2}$ (Schwarz et al., 2002). Maturation of focal adhesions is a slow process that can take up to $60 \mathrm{~min}$ (Zamir et al., 1999) corresponding to a 7 fold force reinforcement (Gallant et al., 2005). This reinforcement is strictly dependent on talin and corresponds to the recruitment of vinculin and paxillin (Giannone et al., 2003). Approximately, focal adhesion areas are proportional to the applied forces (Schwarz et al., 2002; Gallant et al., 2005). Internal tensions that promote focal adhesion assembly can be replaced by external forces application. Conversely, reduction of contractile forces is a prerequisite for remodeling of the actin cytoskeleton including focal adhesion disassembly (Riveline et al., 2001). Tension will activate the tyrosine phosphatase RPTPa that in turn will activate SFK allowing its interaction with focal adhesion kinase (FAK). Phospho FAK will recruit paxillin that in turn will allow a negative feedback implying the activation of Rac1 and the simultaneous inactivation of RhoA (Schober et al., 2007).

Conversely to what is observed with focal adhesions, podosome type adhesions seem to be promoted by decrease in local cellular contractility (Lener et al., 2006; Linder, 2007). For instance A7r5 smooth muscle cells simultaneously display contractile activity in the cell center and motile activity in the cell periphery with reduced tension. This allows peripheral remodeling of actin cytoskeleton resulting of the dispersal of focal adhesions and the formation of dynamic podosomes at the same sites (Hai et al., 2002; Kaverina et al., 2003; Burgstaller and Gimona, 2004). This process is correlated with the local dispersion of contractile proteins including myosin, tropomyosin, and h1calponin, and the recruitment of p190RhoGAP to podosome sites (Lener et al., 2006). The specific subcellular localization of p190RhoGAP, together with its tyrosine phosphorylation, is an important determinant for its activation (Brouns et al., 2001; Haskell et al., 2001) and the inhibition of RhoA which result in the subsequent decrease in contractility (Peacock, 2007). Consistent with the observation in smooth muscle cells, in neuroblastoma the activation of TRPM7, an a kinase coupled with a calcium channel, results in the phosphorylation of the heavy chain of myosin II and the transformation of focal adhesions into podosomes similarly to what is observed by pharmacodynamically inhibiting myosin II (Clark et al., 2006). Although intracellular tensions seem not to be required for podosome assembly, their lifespan and mean minimum distance between them depend on the substrate flexibility as well as the speed of the podosome ring expansion in GFP-actin transfected NIH 3T3 cells, suggesting that intracellular constraints may play a role in the collective dynamic of these structures (Collin et al., 2006). Indeed, high-resolution scanning electron microscopy combined with fluorescence microscopy has allowed to resolve the molecular architecture of podosome arrays and to show that these adhesive structures communicate through a network of actin filaments parallel to the substrate suggesting the existence of tangential forces between podosome actin cores ( Luxenburg et al., 2007). Focal adhesion dynamics also appear to be tightly linked to matrix assembly and affected by the physical properties of the substrate. Indeed, formation of fibrillar adhesions and development of fibronectin fibrils occur when cells are plated on native fibronectin, whereas cells plated on covalently immobilized fibronectin do not form fibrillar adhesions (Katz et al., 2000). Moreover, increase in substrate density accelerates focal adhesion assembly, a process that is dependent on ICAP-1. This allows the matrix surface density sensing by the cell permitting its adaptive response to changes in the properties of the ECM (Millon-Fremillon et al., 2008 ).

\section{Adhesion sites dynamics and cell migration}

\section{Individual versus collective dynamics}

Because of their involvement in cell motility and matrix remodeling or matrix degradation, adhesion sites are necessarily dynamic structures able to assemble and disassemble (Fig. 2). To migrate, cells that develop focal adhesions initially extend a directed protrusion at the leading edge through the localized polymerization of actin and subsequent integrin-mediated stabilization of adhesions. After stabilization of the protrusion or lamellipodium, cells generate tensions and the contractile force is required for cell movement. The final step in the migratory cycle involves release of adhesions at the rear of the cell to allow forward progression. These classical steps are 
representative of the 2D migratory cycle of many adherent cells such as fibroblasts. In contrast, migrating leucocytes and more generally cells able to develop podosomes tend to display a more gliding movement. Disregarding the adhesion type assembled, the migration speed seems to be inversely proportional to the internal tension developed, i.e., $200 \mathrm{nN}$ for a fibroblast speed of $0.5 \mu \mathrm{m} / \mathrm{sec}$ versus $20 \mathrm{nN}$ for a keratinocyte migrating at $170 \mu \mathrm{m} / \mathrm{sec}$ (Isabey, D. personal communication). Focal adhesion lifetime is about 30-90 min (Fig. 2A). Assembly/disassembly of podosomes are much more dynamic than those of focal adhesions, with lifespan on the order of 2-12 minutes ( Destaing et al., 2003). Invadopodia found in carcinoma are distinguishable from podosomes by a remarkable persistence going up to 1 hour or more (Yamaguchi et al., 2005), and the induction of a more focused and deeper degradation of extracellular matrix (Table 1). Nevertheless invadopodia lifespan can be shortened by orthovanadate treatment up to the characteristic podosome lifetime (Fig. 2B). So far, studies addressing the dynamics of adhesions during migration have shed some light on the different adhesions processes. With a growing number of transgenic mice available, the role of individual adhesion molecule in the organization and dynamics of adhesive structure can be addressed ex vivo, and correlated with physiological functions in vivo. Such studies underline a spatiotemporal coordination of the adhesion structures between the front and the rear of migrating cells, and also between the external and internal rim of the rosettes. These observations emphasize two control levels: dynamics of individual focal adhesions or isolated podosomes, and collective dynamics of these adhesion structures (Table 1). For instance, collective dynamics can be imaged by the actin stress fibers mediated connection of "towing adhesions" in the front of the cell fibers with sliding trailing adhesions at the rear of the cell. Trailing adhesions actively generated at the rear of the cell are necessary for persistent forward movement of fibroblasts (Rid et al., 2005). Collective dynamics allow also the organization of podosome clusters into rosettes or the coordination between focal adhesions at the front and those at the rear of migrating cells. It is noteworthy that increase in tyrosine phosphorylation most likely by Src kinase, results in both enhancement of podosome assembly and disassembly resulting in the acceleration of PTA rosette expansion while keeping the rosette width constant (Badowski et al., 2008). These coordinated processes are required for efficient extracellular matrix degradation and transmigration through a cell monolayer (Saltel et al., 2006; Badowski et al., 2008). Actin dynamics is likely to play a major role in this organization and coordination as suggested by the actin cables able to maintain individual podosomes (Luxenburg et al., 2007) or stress fibers that connect focal adhesions. Dynamics of adhesion structures is the common denominator that allows a fast adaptive response to external or internal stimuli, and supports cell shape and/or cell migration. Such response is regulated by several switches controlling signaling pathways such as GTPases, lipid, proteolytic and phosphorylation switches. Depending on the type of adhesions, the external stimuli transmitted by extracellular matrix is perceived differently and will induce a completely distinct cell response: matrix reorganization and fibronectin fibrillogenesis in case of fibrillar adhesions, or matrix degradation with podosome type adhesions.

\section{Actin polymerization}

Two distinct actin networks drive the protrusion of migrating cells (Ponti et al., 2004). Extension of the leading edge is characterized by a cyclic process: the protrusion of lamellipodium associated with a dense network of branching actin filaments is followed by the formation of focal adhesions at the rear of the lamellipodium with the assembly of stress fibers in the lamellum area (Giannone et al., 2007 ). Actin network undergoes a fast retrograde flow in the lamellipodium allowing actin polymerization and depolymerisation whereas a slower centripetal flow is observed in the actomyosin contraction associated lamellum. The transition between these two types of actin network is unknown but focal complexes are localized in the lamellipodium whereas newly formed focal adhesions are localized at the interface between the lamellipodia and lamella F-actin networks (Hu et al., 2007).

At this boundary, myosin II pulls the rear of the lamellipodial actin network, causing upward bending, edge retraction, and initiation of new adhesion sites (Giannone et al., 2007). On the other hand, integrin occupancy in filopodia favors actin nucleation and dendritic polymerization through Rac signaling (Galbraith et al., 2007; Guillou et al., 2008). Additionally, a number of components of focal adhesions seem to promote actin nucleation such as paxillin, which couples the SH2/SH3 adaptor protein CrkII to N-WASp to allow its activation by the small GTPase cdc42 (Tang et al., 2003; Tang and Gunst, 2004; Zhang et al., 2005), FAK that associates with the Arp2/3 complex and colocalizes at transient structures formed early after adhesion in nascent lamellipodia (Serrels et al., 2007), or vinculin that can bind and seems to regulate Arp2/3 nucleation activity (DeMali and Burridge, 2003). In spite of Arp2/3 interaction with proteins localized in focal adhesion, neither Arp2/3 nor WASP has been localized in focal adhesions structures (Table I). Interestingly, mature focal adhesions themselves seem not to be actual nucleation sites, and conversely to podosome type adhesions, they seem not to be so dependent on actin polymerization. Finally, specific actin-binding proteins within focal adhesions may link F-actin in the lamella to transmembrane integrins (Critchley et al., 1999) that bind the extracellular matrix, stabilizing leading edge protrusions in the second step of migration.

During osteoclast polarization, podosomes undergo reorganization from a scattered distribution, through the formation of clusters and ring super-structures, to the assembly of a sealing zone at the cell periphery. The enhanced dynamic reorganization of podosomes during osteoclast polarization is inversely related to the local levels of tyrosine phosphorylation of the Src substrate, cortactin (Luxenburg et al., 2006). Podosome belts are composed of two F-actin-containing domains, namely, a diffuse actin cloud surrounding actin dots referred to as podosome cores. Comparisons between WT and WIP ${ }^{-/-}$osteoclast phenotypes allowed to separate these two F-actin domains and to show for the first time that they fulfill different roles (Chabadel et al., 2007). The actin cloud linked to vinculin, paxillin, signaling phosphoproteins, together with the $\alpha_{\mathrm{v}} \beta_{3}$ integrin interacts with extracellular matrix and regulates osteoclast contractility in part through myosin II. In contrast, podosome cores made of a dense F-actin network associated with cortactin, Arp2/3, WASp, and the transmembrane 
receptor CD44, which could establish an initial adhesion via CD44/hyaluronate. In parallel, in the absence of Src(s) activities in osteoclasts, podosomes cores are formed but are devoid of actin cloud. Thus, it appears that the main molecular regulator of the actin cloud is the tyrosine kinase activity of Src (Destaing et al., 2008).

\section{Assembly of cell matrix adhesions}

Focal adhesions assembly starts with integrin occupancy and clustering to finally connect to actin stress fibers while at least assembly of podosome type adhesion of RSV transformed BHK cells is initiated by the nucleation of an actin column perpendicular to the plasma membrane that undergoes continuous cycles of polymerization and depolymerization (Badowski et al., 2008) and constitutes the PTA core. Overexpression of cortactin, mutated at its major Src phosphorylation sites, enhanced actin turnover, suggesting that podosome dynamics in osteoclasts can be down regulated by Src dependent cortactin phosphorylation (Luxenburg et al., 2006). On the other hand, it was recently shown that cortactin phosphorylation by Src enhances actin assembly and thereby could favor the appearance of new podosomes ( Tehrani et al., 2007). Conversely, it is also well known that cortactin does not accumulate in focal adhesions but in lamellipodia where the polymerized F-actin meshwork pushes the membrane of migrating cells (Bryce et al., 2005). Therefore cortactin emerged as a key protein involved in the coordination of membrane dynamics with the actin cytoskeleton remodeling. Although the exact mechanisms underlying its fundamental roles remain to be defined, cortactin is likely to act via the Arp2/3 complex. Indeed, Arp2/3 knock down in osteoclast leads to an impairment in podosome formation (Hurst et al., 2004).

CD44 was recently identified in podosome core of osteoclasts (Chabadel et al., 2007) and seems to strengthen adhesion to the substrate through its affinity for hyaluronan, a glycosaminoglycan constituent of extracellular matrix, but also potentially through its affinity for other ligands such as osteopontin, collagens and matrix metalloproteases (Cichy and Pure, 2003). Since the actin core seems to appear before formation of the integrin rich surrounding ring in Src-transformed BHK cells, CD44 could play the role of an initial adhesion. Similarly, in addition to integrins, proteoglycan, glycosaminoglycan receptors were recently reported to localize at focal adhesions and induce an initial adhesion mediated by hyaluronate before the formation of adhesion structures driven by integrins (Cohen et al., 2006). Another hyaluronan receptor named Layilin that interacts with talin and other ERM protein may play in the case of focal adhesions, a similar role than CD44 in podosomes (Borowsky and Hynes, 1998; Bono et al., 2001; Bono et al., 2005).

Genetic and biophysical analyses have also established important roles for talin in focal adhesion initiation, reinforcement and stabilization (Albiges-Rizo et al., 1995; Priddle et al., 1998; Giannone et al., 2003; Jiang et al., 2003), as well as in integrin activation and local phosphatidyl-4,5 bis-phosphate generation (Martel et al., 2001; Yan et al., 2001; Calderwood et al., 2002; Tadokoro et al., 2003). Indeed, integrin clustering requires the formation of the complex made of activated integrins, immobilized ligands, talin and PIP ${ }_{2}\left(C_{\text {Cluzel }}\right.$ et al., 2005). Recent data suggest that the binding of a complex including talin, RIAM, Rap1 and VASP to the integrin cytoplasmic tail is a common final step in integrin activation (Han et al., 2006). Recently, it has also been proposed a new model where vinculin has a key role in focal adhesion formation and turnover: vinculin head regulates integrin dynamics and clustering whereas the tail regulates the link to the mechantransduction force machinery (Humphries et al., 2007). On the other hand, a low affinity switch of $\beta_{1}$ integrins is controlled by ICAP-1, a cytoplasmic partner, (likely by competing with talin). ICAP-1 delays focal adhesion assembly and, consequently, hampers cell spreading and migration (Bouvard et al., 2003; Millon-Fremillon et al., 2008). Integrin occupancy resulting in the recruitment of talin, vinculin, and paxillin is also observed in PTA as soon as the actin column has pushed the membrane in close contact with extracellular matrix (Badowski et al., 2008).

The subsequent molecular mechanisms that lead to PTA and focal adhesions assembly have been partly characterized. They require Rho family GTPases, coordinated interaction between integrins and structural/signaling molecules, as well as actin-binding proteins ( Chellaiah et al., 2000; Moreau et al., 2003; Raftopoulou and Hall, 2004; Destaing et al., 2005; Yamaguchi et al., 2005; Gimona and Buccione, 2006). The importance of these molecules as regulators is underscored by studies of knockout mice phenotypes showing abnormalities in cell migration and spreading.

In focal adhesions, PAK and PIX play a pivotal role in the maintenance of paxillin-containing focal adhesions (Stofega et al., 2004) and their turnover (for review see (Rosenberger and Kutsche, 2006). Further insight into the PIX-dependent molecular mechanisms required for actin reorganization and focal adhesion formation came from the identification of a novel protein family consisting of $G$ protein-coupled receptor kinase-interacting target (GIT), paxillin kinase linker (p95PKL), ADP-ribosylation factor (Arf)-GAP-putative PIX-interacting, paxillin-interacting protein (p95-APP), and Cool-associated, tyrosine phosphorylated protein (CAT) (Bagrodia and Cerione, 1999; Turner et al., 1999; Di Cesare et al., 2000; Premont et al., 2000; Paris et al., 2003). Furthermore, complexes of GIT-PIXPAK have been shown to cycle between at least three distinct subcellular compartments, including focal adhesions, a cytoplasmic (vesicular) compartment, and the leading edge (Di Cesare et al., 2000; Matafora et al., 2001; Manabe et al., 2002).

Comparably, the RhoGTPase effector PAK4, a member of the p21 associated kinase family, and its regulator aPIX (PAK-interacting exchange factor), are important for podosome formation in primary human macrophages. Knockdown experiments, as well as expression of PAK4 truncation mutants, resulted in reduced numbers of podosomes per cell. Moreover, expression of kinase active or inactive PAK4 
mutants enhanced or reduced the size of individual podosomes in macrophages, respectively, indicating an influence of PAK4 kinase activity on podosome size (Gringel et al., 2006). Expression of active constructs of PAK1 is also able to induce the formation of dynamic, podosome-like F-actin columns in the A7r5 vascular smooth muscle cell line (Webb et al., 2005).

Protein kinases and phosphatases regulate migration by modulating phosphorylation and dephosphorylation of key regulatory molecules. Podosome/invadopodia (PTA) dynamics and functions were reported to be regulated by Src-induced tyrosine phosphorylations (Marchisio et al., 1984; Tarone et al., 1985; Mueller et al., 1992; Linder and Aepfelbacher, 2003; Bowden et al., 2006). A key function of Src in osteoclasts is to promote the rapid assembly and disassembly of podosomes (Horne et al., 2005). After integrin engagement, Pyk2 recruits $\mathrm{Src}$ and the adaptor protein $\mathrm{Cbl}$, forming a molecular signaling complex that is critical for cell migration, and deletion of any molecule in this complex disrupts podosome ring formation and/or decreases osteoclast migration. The Cbl proteins in turn recruit and activate additional signaling effectors, including phosphatidylinositol 3-kinase (Fukazawa et al., 1995; Soltoff and Cantley, 1996) and dynamin (Bruzzaniti et al., 2005), which play key roles in the development of cell polarity and the regulation of cell attachment and motility.

\section{Disassembly of cell-matrix adhesions}

Fibroblasts deficient in FAK, Src family kinases (Src, Yes, Fyn), (PTP)-PEST, or SHP2 expression exhibit a decrease in the rate of migration and spreading and an increase in the number and size of peripherally localized focal adhesions (Ilic et al., 1995; Yu et al., 1998; Angers-Loustau et al., 1999; Klinghoffer et al., 1999). In addition, live cell imaging studies underline the crucial role of some kinases and adaptor molecules, such as FAK, Src, p130Cas, paxillin, extracellular signal-regulated kinase (ERK) and myosin light-chain kinase (MLCK) in adhesion turnover at the cell front, a central process of cell migration (Webb et al., 2004). In osteoclasts, the absence of a number of proteins components including Src, Cbl, Pyk2, $\beta_{3}$ integrin, RhoA and gelsolin reduces osteoclast bone-resorbing activity to various degrees and the ability to form podosomes rosettes and sealing zone (Soriano et al., 1991; Chellaiah et al., 2000; Chiusaroli et al., 2003). In Src-/- osteoclasts, the peripheral podosome belt is absent and replaced by irregular podosome patches at the cell center, likely due to a decrease in podosome number and/or altered dynamics exemplified by the four fold increase in the average podosome life span ( Destaing et al., 2008). Indeed, Src is also a main regulator of the disassembly of focal adhesions and podosomes (Webb et al., 2004; Luxenburg et al., 2006; Destaing et al., 2008). A similar pattern has been observed in case of knock-down of many components of podosome ring such as paxillin (Badowski et al., 2008), meaning that the incapacity to form ring or belt is the signature of a defect in podosome type adhesion dynamics. Similarly to podosome distribution during osteoclast differentiation, in RSV-transformed BHK cells, invadopodia can also self-organize into rosettes and belts, under the control of tyrosine phosphorylation whereas in carcinoma cells invadopodia remain as individual structures. In the BHK-RSV model, it has been clearly established that the composition of individual invadopodia is spatiotemporally regulated and depends on invadopodia localization along the rosette section: the actin core assembly precedes the recruitment of surrounding integrins and integrin-linked proteins while the loss of the actin core was a prerequisite to invadopodia disassembly. Invadopodia rosette expansion is controlled by paxillin phosphorylations on tyrosine 31 and 118 by the FAK/Src complex which allows invadopodia disassembly. The lack of paxillin phosphorylation, or calpain or Erk inhibition result in similar phenotype, suggesting that these proteins belong to the same regulatory pathways (Badowski et al., 2008). Surprisingly, this mechanism seems to be quite similar in focal adhesions where paxillin also plays a major role in their disassembly (Zaidel-Bar et al., 2007). Indeed, recent studies have demonstrated that the calpain family has a regulatory function in cell motility, partly through the capacity to down regulate integrin-mediated adhesion complexes (Glading et al., 2000; Dourdin et al., 2001; Bhatt et al., 2002; Glading et al., 2002). In that context, talin seems to be one of major target of calpain leading to a rate-limiting step critical for FA disassembly (Franco et al., 2004). It has also been shown that the expression of a calpain-resistent cortactin impaired cell migration and increased transient membrane protrusion (Perrin et al., 2006). Since cortactin is a major component of PTA, its degradation by calpain may play a key role in their disassembly. In addition, PTA turnover depends on degradation of WASP by calpain (Calle et al., 2006) and on its stabilization by WIP ( Chou et al., 2006). Lifetime and maturation of invadopodia are influenced by cofilin. Loss of cofilin leads to short-lived invadopodia and decreased matrix degradation in carcinoma cells (Yamaguchi et al., 2005), suggesting cofilin as a key protein for transition between podosomes and invadopodia.

Microtubules have also been shown to stimulate focal adhesions disassembly (Kaverina et al., 1999). More recently Ezratty et al ( Ezratty et al., 2005) have demonstrated that microtubule-induced focal adhesion disruption may occur independently of Rho A and Rac 1, but is dependent on FAK and dynamin, which might drive disassembly through integrin endocytosis. Microtubules also affect turnover of podosomes. The formation of the peripheral podosome belt in osteoclasts depends on an intact microtubule system involving Rho, the formin mDia2 and histone deacetylase (HDAC6), through regulation of the acetylation level of microtubules (Destaing et al., 2005). Similarly to the targeting of focal adhesions by microtubules for their dissolution (Kaverina et al., 1999; Krylyshkina et al., 2003), macrophage podosomes are also targeted by microtubules plus ends influencing not only their breakdown but also podosome generation by a dissolution/fission process (Kopp et al., 2006). However, other data although indicating a clear relationship between microtubules and podosomes suggest that podosomes fission/fusion may be influenced by nocodazole (a microtubules depolymerizing agent) or paclitaxel (a microtubules stabilizing agent) without any effect in dissolution of individual podosomes (Evans et al., 2003). Microtubules probably deliver materials not yet identified in the case of focal adhesions. For podosomes, KIF1C may allow the delivery of lysosomal material ( 
Poincloux et al., 2006) or trafficking of MMPs (Schnaeker et al., 2004). Moreover, KIF1C provides an interface together with Myosin IIA between microfilaments and microtubules (Gringel et al., 2006).

Dynamin, a GTPase essential for endocytosis, is also involved in actin cytoskeleton remodeling and is localized to podosomes where it plays a role in actin turnover. Dynamin colocalizes with $\mathrm{Cbl}$ in the actin-rich podosome belt of osteoclasts (Bruzzaniti et al., 2005). Phosphorylated $\mathrm{Cbl}$ is also able to recruit Crk adapter proteins (Horne et al., 2005) and the guanine nucleotide exchange factor vav ( Marengere et al., 1997), and possibly Src and other Src family kinases (Feshchenko et al., 1998). In focal adhesions, it has also been suggested that Cbl-mediated ubiquitination plays an essential role in $\alpha_{5}$ integrin proteasome degradation induced by FGFR2 activation ( Kaabeche et al., 2005). In addition, ArgBP2 interacts with $\mathrm{Cbl}$ and colocalizes with actin on stress fibers and at cell-adhesion sites. The ArgBP2 partners include dynamin, synaptojanin and WAVE isoforms, as well as WAVE regulatory proteins. ArgBP2/nArgBP2 knockdown in astrocytes produces a redistribution of focal adhesion proteins and an increase in peripheral actin ruffles, whereas nArgBP2 overexpression produces a collapse of the actin cytoskeleton. Thus, ArgBP2 is a scaffold protein that controls the balance between adhesion and motility by coordinating the function of multiple signaling pathways converging on the actin cytoskeleton (Cestra et al., 2005 ) .

\section{Conclusions}

Although extensively studied, focal adhesions and podosomes have rarely been compared. While they exhibit very distinct structures, recent data in the literature suggest surprisingly convergent regulatory mechanisms of their dynamics. However, the study of different matrix adhesions with distinct morphologies, compositions and dynamics may shed light on their capacity to activate or respond to distinct signaling pathways and their specific functions. Nevertheless, interplay between both structures has been evidenced. Future challenges will include the determination of how dynamic processes are involved in the formation and transformation or conversion of matrix adhesions highlighting the plasticity of cell matrix contacts in a variety of biological responses in different tissue, under physiological and pathological situations. One will have to address how regulatory molecules or external constraints in cell-matrix adhesion may contribute to promote or impair distinct adhesive structures. Finally, it will be important to understand how focal adhesions, podosomes and invadopodia function cooperatively during tumor invasion.

\section{Ackowledgements:}

The team is supported by a grant from the Ligue Nationale Contre le Cancer, the Association de Recherche pour le Cancer, GEFLUC, ANR, and the Région Rhône-Alpes. A. M.-F. was supported by a fellowship from the Ministère de l'Education Nationale, de la Recherche et de la Technologie. C.B. was supported by grants from the Ministère de l'Education Nationale, de la Recherche et de la Technologie and from the Association de Recherche pour le Cancer. D. G.-S. was supported by the Ligue Nationale Contre le Cancer. We thank E. Van ObberghenSchilling and O. Destaing for critical reading of the manuscript.

\section{References:}

- Abercrombie M , Heaysman JE, Pegrum SM 1971; The locomotion of fibroblasts in culture. IV. Electron microscopy of the leading lamella. Exp Cell Res. 67: 359- 367

- Albiges-Rizo C , Frachet P, Block MR 1995; Down regulation of talin alters cell adhesion and the processing of the alpha 5 beta 1 integrin. J Cell Sci. 108: $3317-3329$

- Angers-Loustau A, Cote JF, Charest A, Dowbenko D, Spencer S, Lasky LA, Tremblay ML 1999; Protein tyrosine phosphatase-PEST regulates focal adhesion disassembly, migration, and cytokinesis in fibroblasts. J Cell Biol. 144: 1019- 1031

- Artym VV, Zhang Y, Seillier-Moiseiwitsch F, Yamada KM , Mueller SC 2006; Dynamic interactions of cortactin and membrane type 1 matrix metalloproteinase at invadopodia: defining the stages of invadopodia formation and function. Cancer Res. 66: 3034- 3043

- Avraham H, Park SY, Schinkmann K, Avraham S 2000; RAFTK/Pyk2-mediated cellular signalling. Cell Signal. 12: 123- 133

- Badowski C, Pawlak G, Grichine A, Chabadel A, Oddou C, Jurdic P, Pfaff M, Albiges-Rizo C, Block MR 2008; Paxillin Phosphorylation Controls Invadopodia/Podosomes Spatiotemporal Organization. Mol Biol Cell.

- Bagrodia S , Cerione RA 1999; Pak to the future [see comments]. Trends Cell Biol. 9: 350- 355

- Baldassarre M, Ayala I, Beznoussenko G, Giacchetti G, Machesky LM, Luini A, Buccione R 2006; Actin dynamics at sites of extracellular matrix degradation. Eur J Cell Biol. 85: 1217- 1231

- Bhatt A , Kaverina I, Otey C , Huttenlocher A 2002; Regulation of focal complex composition and disassembly by the calcium-dependent protease calpain. J Cell Sci. 115: 3415- 3425

- Bono P, Cordero E, Johnson K, Borowsky M, Ramesh V, Jacks T, Hynes RO 2005; Layilin, a cell surface hyaluronan receptor, interacts with merlin and radixin. Exp Cell Res. 308: 177- 187

- Bono P , Rubin K, Higgins JM , Hynes RO 2001; Layilin, a novel integral membrane protein, is a hyaluronan receptor. Mol Biol Cell. 12: 891 - 900

- Borowsky ML, Hynes RO 1998; Layilin, a novel talin-binding transmembrane protein homologous with C- type lectins, is localized in membrane ruffles. J Cell Biol. 143: 429 $-442$

- Boulter E, Van Obberghen-Schilling 2006; Integrin-linked kinase and its partner: A modular platform regulating cell-matrix adhesion dynamics and cytoskeletal organization. Eur J Cell Biol. 85: 255- 63

- Bouvard D, Aszodi A, Kostka G, Block MR, Albiges-Rizo C, Fassler R 2007; Defective osteoblast function in ICAP-1-deficient mice. Development.

- Bouvard D, Vignoud L, Dupe-Manet S, Abed N, Fournier HN , Vincent-Monegat C, Retta SF, Fassler R, Block MR 2003; Disruption of focal adhesions by integrin cytoplasmic domain-associated protein-1 alpha. J Biol Chem. 278: 6567- 6574

- Bowden ET , Barth M, Thomas D, Glazer RI , Mueller SC 1999; An invasion-related complex of cortactin, paxillin and PKCmu associates with invadopodia at sites of extracellular matrix degradation. Oncogene. 18: 4440- 4449

- Bowden ET , Onikoyi E, Slack R, Myoui A, Yoneda T, Yamada KM , Mueller SC 2006; Co-localization of cortactin and phosphotyrosine identifies active invadopodia in human breast cancer cells. Exp Cell Res. 312: 1240- 1253

- Brazier H , Stephens S, Ory S, Fort P, Morrison N , Blangy A 2006; Expression profile of RhoGTPases and RhoGEFs during RANKL-stimulated osteoclastogenesis: identification of essential genes in osteoclasts. J Bone Miner Res. 21: 1387- 1398 
- Brouns MR, Matheson SF, Settleman J 2001; p190 RhoGAP is the principal Src substrate in brain and regulates axon outgrowth, guidance and fasciculation. Nat Cell Biol. 3: 361- 367

- Brown MC, Turner CE 2004; Paxillin: adapting to change. Physiological reviews. 84: 1315- 1339

- Bruzzaniti A, Neff L, Sanjay A, Horne WC, De Camilli P, Baron R 2005; Dynamin forms a Src kinase-sensitive complex with Cbl and regulates podosomes and osteoclast activity. Mol Biol Cell. 16: 3301- 3313

- Bryce NS , Clark ES , Leysath JL, Currie JD , Webb DJ , Weaver AM 2005; Cortactin promotes cell motility by enhancing lamellipodial persistence. Curr Biol. 15: 12761285

- Buccione R , Orth JD , McNiven MA 2004; Foot and mouth: podosomes, invadopodia and circular dorsal ruffles. Nat Rev Mol Cell Biol. 5: 647- 657

- Burgstaller G, Gimona M 2004; Actin cytoskeleton remodelling via local inhibition of contractility at discrete microdomains. J Cell Sci. 117: 223- 231

- Burridge K , Chrzanowska-Wodnicka M 1996; Focal adhesions, contractility, and signaling. Annu Rev Cell Dev Biol. 12: 463- 518

- Buruinsma R 2005; Theory of Force Regulation by Nascent Adhesion Sites. Biophysical Journal. 89: 87- 94

- Calderwood DA, Yan B, de Pereda JM, Alvarez BG, Fujioka Y, Liddington RC, Ginsberg MH 2002; The phosphotyrosine binding-like domain of talin activates integrins. J Biol Chem. 277: 21749- 21758

- Calle Y, Carragher NO, Thrasher AJ , Jones GE 2006; Inhibition of calpain stabilises podosomes and impairs dendritic cell motility. J Cell Sci. 119: 2375- 2385

- Carman CV , Sage PT , Sciuto TE, de la Fuente MA, Geha RS , Ochs HD, Dvorak HF, Dvorak AM , Springer TA 2007; Transcellular diapedesis is initiated by invasive podosomes. Immunity. 26: 784- 797

- Cestra G, Toomre D, Chang S, De Camilli P 2005; The Abl/Arg substrate ArgBP2/nArgBP2 coordinates the function of multiple regulatory mechanisms converging on the actin cytoskeleton. Proc Natl Acad Sci U S A. 102: 1731- 1736

- Chabadel A, Banon-Rodriguez I, Cluet D, Rudkin BB, Wehrle-Haller B, Genot E, Jurdic P, Anton IM , Saltel F 2007 ; CD44 and beta3 Integrin Organize Two Functionally Distinct Actin-based Domains in Osteoclasts. Mol Biol Cell. 18: 4899- 4910

- Chellaiah M, Kizer N, Silva M, Alvarez U , Kwiatkowski D, Hruska KA 2000; Gelsolin deficiency blocks podosome assembly and produces increased bone mass and strength. J Cell Biol. 148: 665- 678

- Chen H , Cohen DM , Choudhury DM , Kioka N , Craig SW 2005; Spatial distribution and functional significance of activated vinculin in living cells. J Cell Biol. 169: 459470

- Chiusaroli R, Sanjay A , Henriksen K, Engsig MT , Horne WC, Gu H , Baron R 2003; Deletion of the gene encoding c-Cbl alters the ability of osteoclasts to migrate, delaying resorption and ossification of cartilage during the development of long bones. Dev Biol. 261: 537- 547

- Chou HC, Anton IM , Holt MR, Curcio C, Lanzardo S, Worth A, Burns S, Thrasher AJ , Jones GE, Calle Y 2006; WIP regulates the stability and localization of WASP to podosomes in migrating dendritic cells. Curr Biol. 16: 2337- 2344

- Cichy J, Pure E 2003; The liberation of CD44. J Cell Biol. 161: 839- 843

- Clark K, Langeslag M, van Leeuwen B , Ran L, Ryazanov AG, Figdor CG, Moolenaar WH , Jalink K, van Leeuwen FN 2006; TRPM7, a novel regulator of actomyosin contractility and cell adhesion. EMBO J. 25: 290- 301

- Cluzel C, Saltel F, Lussi J, Paulhe F, Imhof BA, Wehrle-Haller B 2005; The mechanisms and dynamics of (alpha)v(beta)3 integrin clustering in living cells. J Cell Biol. 171: 383- 392

- Cohen DM , Kutscher B , Chen H , Murphy DB , Craig SW 2006; A conformational switch in vinculin drives formation and dynamics of a talin-vinculin complex at focal adhesions. J Biol Chem. 281: 16006- 16015

- Collin O, Tracqui P, Stephanou A, Usson Y, Clement-Lacroix J, Planus E 2006; Spatiotemporal dynamics of actin-rich adhesion microdomains: influence of substrate flexibility. J Cell Sci. 119: 1914- 1925

- Critchley DR , Holt MR , Barry ST , Priddle H , Hemmings L, Norman J 1999; Integrin-mediated cell adhesion: the cytoskeletal connection. Biochem Soc Symp. 65: 79- 99

- Cukierman E , Pankov R , Stevens DR , Yamada KM 2001; Taking cell-matrix adhesions to the third dimension. Science. 294: 1708- 1712

- DeMali KA, Burridge K 2003; Coupling membrane protrusion and cell adhesion. J Cell Sci. 116: 2389- 2397

- Destaing O, Saltel F, Geminard JC, Jurdic P , Bard F 2003; Podosomes display actin turnover and dynamic self-organization in osteoclasts expressing actin-green fluorescent protein. Mol Biol Cell. 14: 407- 416

- Destaing O, Saltel F, Gilquin B , Chabadel A, Khochbin S, Ory S , Jurdic P 2005; A novel Rho-mDia2-HDAC6 pathway controls podosome patterning through microtubule acetylation in osteoclasts. J Cell Sci. 118: 2901- 2911

- Destaing O, Sanjay A, Itzstein C, Horne WC, Toomre D, De Camilli P, Baron R 2008; The Tyrosine Kinase Activity of c-Src Regulates Actin Dynamics and Organization of Podosomes in Osteoclasts. Mol Biol Cell. 19: 394- 404

- Di Cesare A, Paris S, Albertinazzi C, Dariozzi S , Andersen J , Mann M , Longhi R, de Curtis I 2000; p95-APP1 links membrane transport to Rac-mediated reorganization of actin. Nat Cell Biol. 2: 521- 530

- Dikic I, Tokiwa G, Lev S, Courtneidge SA, Schlessinger J 1996; A role for Pyk2 and Src in linking G-protein-coupled receptors with MAP kinase activation. Nature. 383: 547- 550

- Dourdin N , Bhatt AK, Dutt P, Greer PA, Arthur JS , Elce JS , Huttenlocher A 2001; Reduced cell migration and disruption of the actin cytoskeleton in calpain-deficient embryonic fibroblasts. J Biol Chem. 276: 48382- 48388

- Du QS , Ren XR , Xie Y, Wang Q , Mei L, Xiong WC 2001; Inhibition of PYK2-induced actin cytoskeleton reorganization, PYK2 autophosphorylation and focal adhesion targeting by FAK. J Cell Sci. 114: 2977- 2987

- Evans JG , Correia I, Krasavina O, Watson N , Matsudaira P 2003; Macrophage podosomes assemble at the leading lamella by growth and fragmentation. J Cell Biol. 161: 697- 705

- Ezratty EJ , Partridge MA , Gundersen GG 2005; Microtubule-induced focal adhesion disassembly is mediated by dynamin and focal adhesion kinase. Nat Cell Biol. 7: 581590

- Feshchenko EA, Langdon WY, Tsygankov AY 1998; Fyn, Yes, and Syk phosphorylation sites in c-Cbl map to the same tyrosine residues that become phosphorylated in activated T cells. J Biol Chem. 273: 8323-8331

- Frame MC , Fincham VJ , Carragher NO, Wyke JA 2002; v-Src's hold over actin and cell adhesions. Nat Rev Mol Cell Biol. 3: $233-245$

- Franco SJ , Rodgers MA, Perrin BJ , Han J, Bennin DA, Critchley DR, Huttenlocher A 2004; Calpain-mediated proteolysis of talin regulates adhesion dynamics. Nat Cell Biol. 6: 977- 983

- Fuchs E, Dowling J, Segre J, Lo SH, Yu QC 1997; Integrators of epidermal growth and differentiation: distinct functions for beta 1 and beta 4 integrins. Current opinion in genetics \& development. 7: 672- 682

- Fukazawa T, Reedquist KA, Trub T, Soltoff S , Panchamoorthy G, Druker B , Cantley L, Shoelson SE, Band H 1995; The SH3 domain-binding T cell tyrosyl phosphoprotein p120. Demonstration of its identity with the c-cbl protooncogene product and in vivo complexes with Fyn, Grb2, and phosphatidylinositol 3-kinase. J Biol Chem. 270: 19141- 19150

- Gaidano G, Bergui L, Schena M, Gaboli M, Cremona O, Marchisio PC, Caligaris-Cappio F 1990; Integrin distribution and cytoskeleton organization in normal and malignant monocytes. Leukemia. 4: 682- 687

- Galbraith CG , Yamada KM , Galbraith JA 2007; Polymerizing actin fibers position integrins primed to probe for adhesion sites. Science. 315 : $992-995$

- Galbraith CG , Yamada KM , Sheetz MP 2002; The relationship between force and focal complex development. J Cell Biol. 159: 695- 705

- Gallant ND , Michael KE , Garcia AJ 2005; Cell adhesion strengthening: contributions of adhesive area, integrin binding, and focal adhesion assembly. Mol Biol Cell. 16: 4329- 4340

- Giannone G, Dubin-Thaler BJ , Rossier O, Cai Y, Chaga O , Jiang G, Beaver W , Dobereiner HG , Freund Y , Borisy G, Sheetz MP 2007; Lamellipodial actin mechanically links myosin activity with adhesion-site formation. Cell. 128: 561- 575 
- Giannone G, Jiang G, Sutton DH, Critchley DR, Sheetz MP 2003; Talin1 is critical for force-dependent reinforcement of initial integrin-cytoskeleton bonds but not tyrosine kinase activation. J Cell Biol. 163: 409- 419

- Gimona M, Buccione R 2006; Adhesions that mediate invasion. Int J Biochem Cell Biol. 38: 1875- 1892

- Glading A , Chang P , Lauffenburger DA, Wells A 2000; Epidermal growth factor receptor activation of calpain is required for fibroblast motility and occurs via an ERK/MAP kinase signaling pathway. J Biol Chem. 275: 2390- 2398

- Glading A, Lauffenburger DA, Wells A 2002; Cutting to the chase: calpain proteases in cell motility. Trends Cell Biol. 12: 46- 54

- Green JA , Yamada KM 2007; Three-dimensional microenvironments modulate fibroblast signaling responses. Advanced drug delivery reviews. 59: $1293-1298$

- Gringel A, Walz D , Rosenberger G, Minden A, Kutsche K, Kopp P, Linder S 2006; PAK4 and alphaPIX determine podosome size and number in macrophages through localized actin regulation. J Cell Physiol. 209: 568- 579

- Guillou H, Depraz-Depland H, Planus E, Vianet B , Chaussy J , Albigès-Rizo C, Block MR 2008; Integrin and Rac1 signaling dependent nucleation of lamellipodia by filopodia unraveled by fibroblast adhesion on micro-patterned extracellular matrix arrays. Exp Cell Res.

- Gupton SL, Waterman-Storer CM 2006; Spatiotemporal Feedback between Actomyosin and Focal-Adhesion Systems Optimizes Rapid Cell Migration. Cell. 125: 1361- 1374

- Hai CM , Hahne P , Harrington EO , Gimona M 2002; Conventional protein kinase C mediates phorbol-dibutyrate-induced cytoskeletal remodeling in a7r5 smooth muscle cells. Exp Cell Res. 280: 64- 74

- Han J , Lim CJ , Watanabe N, Soriani A, Ratnikov B , Calderwood DA, Puzon-McLaughlin W , Lafuente EM , Boussiotis VA , Shattil SJ , Ginsberg MH 2006; Reconstructing and deconstructing agonist-induced activation of integrin alphaIIbbeta3. Curr Biol. 16: 1796- 1806

- Haskell MD , Nickles AL , Agati JM , Su L, Dukes BD , Parsons SJ 2001; Phosphorylation of p190 on Tyr1105 by c-Src is necessary but not sufficient for EGF-induced actin disassembly in C3H10T1/2 fibroblasts. J Cell Sci. 114: 1699- 1708

- Horne WC, Sanjay A, Bruzzaniti A, Baron R 2005; The role(s) of Src kinase and Cbl proteins in the regulation of osteoclast differentiation and function. Immunol Rev. 208: $106-125$

- Hu K, Ji L , Applegate KT , Danuser G, Waterman-Storer CM 2007; Differential transmission of actin motion within focal adhesions. Science. 315 : 111 - 115

- Humphries JD , Wang P, Streuli C, Geiger B , Humphries MJ , Ballestrem C 2007; Vinculin controls focal adhesion formation by direct interactions with talin and actin. J Cell Biol. 179: 1043- 1057

- Hurst IR , Zuo J , Jiang J , Holliday LS 2004; Actin-related protein 2/3 complex is required for actin ring formation. J Bone Miner Res. 19: 499- 506

- Huttenlocher A , Ginsberg MH , Horwitz AF 1996; Modulation of cell migration by integrin-mediated cytoskeletal linkages and ligand-binding affinity. J Cell Biol. 134: 15511562

- Ilic D , Furuta Y, Kanazawa S, Takeda N , Sobue K, Nakatsuji N , Nomura S, Fujimoto J , Okada M , Yamamoto T 1995; Reduced cell motility and enhanced focal adhesion contact formation in cells from FAK-deficient mice. Nature. 377: 539- 544

- Izard T, Evans G, Borgon RA, Rush CL, Bricogne G, Bois PR 2004; Vinculin activation by talin through helical bundle conversion. Nature. 427 : 171 - 175

- Jiang G, Giannone G, Critchley DR , Fukumoto E, Sheetz MP 2003; Two-piconewton slip bond between fibronectin and the cytoskeleton depends on talin. Nature. 424: 334 $-337$

- Kaabeche K, Guenou H , Bouvard D, Didelot N , Listrat A, Marie PJ 2005; Cblmediated ubiquitination of alpha5 integrin subunit mediates fibronectin-dependent osteoblast detachment and apoptosis induced by FGFR2 activation. J Cell Sci. 118: 1223- 1232

- Katoh K , Kano Y, Amano M , Kaibuchi K, Fujiwara K 2001; Stress fiber organization regulated by MLCK and Rho-kinase in cultured human fibroblasts. Am J Physiol Cell Physiol. 280: C1669- 1679

- Katz BZ , Zamir E, Bershadsky A, Kam Z, Yamada KM , Geiger B 2000; Physical state of the extracellular matrix regulates the structure and molecular composition of cell-matrix adhesions. Mol Biol Cell. 11: 1047- 1060

- Kaverina I , Krylyshkina O , Small JV 1999; Microtubule targeting of substrate contacts promotes their relaxation and dissociation. J Cell Biol. 146: 1033- 1044

- Kaverina I , Stradal TE , Gimona M 2003; Podosome formation in cultured A7r5 vascular smooth muscle cells requires Arp2/3-dependent de-novo actin polymerization at discrete microdomains. J Cell Sci. 116: 4915- 4924

- Kimura K , Ito M , Amano M , Chihara K, Fukata Y, Nakafuku M , Yamamori B , Feng J , Nakano T , Okawa K , Iwamatsu A , Kaibuchi K 1996; Regulation of myosin phosphatase by Rho and Rho-associated kinase (Rho- kinase) [see comments]. Science. 273: 245- 248

- Kirchner J , Kam Z, Tzur G , Bershadsky AD , Geiger B 2003; Live-cell monitoring of tyrosine phosphorylation in focal adhesions following microtubule disruption. J Cell Sci. 116: $975-986$

- Klinghoffer RA, Sachsenmaier C, Cooper JA, Soriano P 1999; Src family kinases are required for integrin but not PDGFR signal transduction. Embo J. 18: 2459 - 2471

- Kopp P, Lammers R, Aepfelbacher M , Woehlke G, Rudel T, Machuy N , Steffen W, Linder S 2006; The kinesin KIF1C and microtubule plus ends regulate podosome dynamics in macrophages. Mol Biol Cell. 17: 2811- 2823

- Krylyshkina O , Anderson KI , Kaverina I, Upmann I , Manstein DJ , Small JV , Toomre DK 2003; Nanometer targeting of microtubules to focal adhesions. J Cell Biol. 161: 853- 859

- Larsen M , Artym VV , Green JA , Yamada KM 2006; The matrix reorganized: extracellular matrix remodeling and integrin signaling. Curr Opin Cell Biol. 18: 463- 471

- Legate KR, Montanez E, Kudlacek O, Fassler R 2006; ILK, PINCH and parvin: the tIPP of integrin signalling. Nat Rev Mol Cell Biol. 7: 20- 31

- Lener T , Burgstaller G , Crimaldi L, Lach S , Gimona M 2006; Matrix-degrading podosomes in smooth muscle cells. Eur J Cell Biol. 85: 183 - 189

- Lev S, Moreno H, Martinez R, Canoll P, Peles E, Musacchio JM, Plowman GD, Rudy B , Schlessinger J 1995; Protein tyrosine kinase PYK2 involved in Ca(2+)- induced regulation of ion channel and MAP kinase functions. Nature. 376: 737- 745

- Linder S 2007; The matrix corroded: podosomes and invadopodia in extracellular matrix degradation. Trends Cell Biol. 17: 107- 117

- Linder S , Aepfelbacher M 2003; Podosomes: adhesion hot-spots of invasive cells. Trends Cell Biol. 13: 376- 385

- Linder S, Higgs H, Hufner K, Schwarz K, Pannicke U, Aepfelbacher M 2000; The polarization defect of Wiskott-Aldrich syndrome macrophages is linked to dislocalization of the Arp2/3 complex. J Immunol. 165: 221- 225

- Linder S , Nelson D, Weiss M , Aepfelbacher M 1999; Wiskott-Aldrich syndrome protein regulates podosomes in primary human macrophages. Proc Natl Acad Sci U S A. 96 : $9648-9653$

- Luxenburg C, Geblinger D, Klein E, Anderson K, Hanein D , Geiger B , Addadi L 2007; The architecture of the adhesive apparatus of cultured osteoclasts: from podosome formation to sealing zone assembly. PLoS ONE. 2: e179-

- Luxenburg C , Parsons JT , Addadi L, Geiger B 2006; Involvement of the Src-cortactin pathway in podosome formation and turnover during polarization of cultured osteoclasts. J Cell Sci. 119: 4878- 4888

- Manabe R , Kovalenko M , Webb DJ , Horwitz AR 2002; GIT1 functions in a motile, multi-molecular signaling complex that regulates protrusive activity and cell migration. J Cell Sci. 115: 1497- 1510

- Marchisio PC, Cirillo D, Naldini L, Primavera MV, Teti A, Zambonin-Zallone A 1984; Cell-substratum interaction of cultured avian osteoclasts is mediated by specific adhesion structures. J Cell Biol. 99: 1696- 1705

- Marengere LE, Mirtsos C, Kozieradzki I, Veillette A, Mak TW, Penninger JM 1997; Proto-oncoprotein Vav interacts with c-Cbl in activated thymocytes and peripheral T cells. J Immunol. 159: 70- 76

- Martel V , Racaud-Sultan C, Dupe S , Marie C, Paulhe F, Galmiche A, Block MR , Albiges-Rizo C 2001; Conformation, localization, and integrin binding of talin depend on its interaction with phosphoinositides. J Biol Chem. 276: 21217- 21227

- Marx J 2006; Cell biology. Podosomes and invadopodia help mobile cells step lively. Science. 312: 1868- 1869

- Matafora V , Paris S , Dariozzi S , de Curtis I 2001; Molecular mechanisms regulating the subcellular localization of p95-APP1 between the endosomal recycling compartment and sites of actin organization at the cell surface. J Cell Sci. 114: 4509- 4520 
- Millon-Fremillon A, Bouvard D, Grichine A, Manet-Dupe S, Block MR, Albiges-Rizo C 2008; Cell adaptive response to extracellular matrix density is controlled by ICAP-1-dependent beta1-integrin affinity. J Cell Biol. 180: 427- 441

- Miyauchi A, Hruska KA, Greenfield EM, Duncan R, Alvarez J , Barattolo R , Colucci S , Zambonin-Zallone A, Teitelbaum SL, Teti A 1990; Osteoclast cytosolic calcium, regulated by voltage-gated calcium channels and extracellular calcium, controls podosome assembly and bone resorption. J Cell Biol. 111: $2543-2552$

- Mizutani K, Miki H , He H, Maruta H , Takenawa T 2002; Essential role of neural Wiskott-Aldrich syndrome protein in podosome formation and degradation of extracellular matrix in src-transformed fibroblasts. Cancer Res. 62: 669- 674

- Moreau V , Tatin F, Varon C, Genot E 2003; Actin can reorganize into podosomes in aortic endothelial cells, a process controlled by Cdc42 and RhoA. Mol Cell Biol. 23 : 6809- 6822

- Mueller SC, Yeh Y, Chen WT 1992; Tyrosine phosphorylation of membrane proteins mediates cellular invasion by transformed cells. J Cell Biol. 119: 1309- 1325

- Okigaki M, Davis C, Falasca M, Harroch S, Felsenfeld DP, Sheetz MP, Schlessinger J 2003; Pyk2 regulates multiple signaling events crucial for macrophage morphology and migration. Proc Natl Acad Sci U S A. 100: 10740- 10745

- Palecek SP , Huttenlocher A, Horwitz AF, Lauffenburger DA 1998; Physical and biochemical regulation of integrin release during rear detachment of migrating cells. J Cell Sci. 111: (Pt 7) 929- 940

- Paris S , Longhi R , Santambrogio P , de Curtis I 2003; Leucine-zipper-mediated homo- and hetero-dimerization of GIT family p95-ARF GTPase-activating protein, PIX-, paxillin-interacting proteins 1 and 2. Biochem J. 372: 391- 398

- Park SY, Avraham HK , Avraham S 2004; RAFTK/Pyk2 activation is mediated by trans-acting autophosphorylation in a Src-independent manner. J Biol Chem. 279: 3331533322

- Paszek MJ , Zahir N , Johnson KR , Lakins JN , Rozenberg GI , Gefen A, Reinhart- King CA , Margulies SS , Dembo M , Boettiger D , Hammer DA , Weaver VM 2005; Tensional homeostasis and the malignant phenotype. Cancer Cell. 8: 241- 254

- Peacock JG, Miller AL, Bradley WD, Rodriguez OC, Webb DJ, Koleske AJ 2007; The Abl-related gene tyrosine kinase acts through p190RhoGAP to inhibit actomyosin contractility and regulate focal adhesion dynamics upon adhesion to fibronectin. Mol Biol Cell. 18: 3860- 72

- Perrin BJ , Amann KJ , Huttenlocher A 2006; Proteolysis of cortactin by calpain regulates membrane protrusion during cell migration. Mol Biol Cell. 17: 239- 250

- Pfaff M , Jurdic P 2001; Podosomes in osteoclast-like cells: structural analysis and cooperative roles of paxillin, proline-rich tyrosine kinase 2 (Pyk2) and integrin alphaVbeta3. J Cell Sci. 114: 2775- 2786

- Pogue-Geile KL, Chen R, Bronner MP, Crnogorac-Jurcevic T , Moyes KW , Dowen S , Otey CA , Crispin DA, George RD , Whitcomb DC , Brentnall TA 2006; Palladin mutation causes familial pancreatic cancer and suggests a new cancer mechanism. PLoS medicine. 3: e516-

- Poincloux R, Vincent C, Labrousse A, Castandet J , Rigo M, Cougoule C, Bordier C, Le Cabec V, Maridonneau-Parini I 2006; Re-arrangements of podosome structures are observed when Hck is activated in myeloid cells. Eur J Cell Biol. 85: 327- 332

- Ponti A, Machacek M, Gupton SL, Waterman-Storer CM , Danuser G 2004; Two distinct actin networks drive the protrusion of migrating cells. Science. 305 : $1782-1786$

- Premont RT , Claing A, Vitale N , Perry SJ , Lefkowitz RJ 2000; The GIT family of ADP-ribosylation factor GTPase-activating proteins. Functional diversity of GIT2 through alternative splicing. J Biol Chem. 275: 22373- 22380

- Priddle H, Hemmings L, Monkley S, Woods A, Patel B , Sutton D, Dunn GA, Zicha D, Critchley DR 1998; Disruption of the talin gene compromises focal adhesion assembly in undifferentiated but not differentiated embryonic stem cells. J Cell Biol. 142: 1121- 1133

- Raftopoulou M , Hall A 2004; Cell migration: Rho GTPases lead the way. Dev Biol. 265: 23- 32

- Rid R , Schiefermeier N , Grigoriev I , Small JV , Kaverina I 2005; The last but not the least: the origin and significance of trailing adhesions in fibroblastic cells. Cell Motil Cytoskeleton. 61: 161- 171

- Ridley AJ , Hall A 1992; The small GTP-binding protein rho regulates the assembly of focal adhesions and actin stress fibers in response to growth factors. Cell. 70: $389-399$

- Riveline D , Zamir E, Balaban NQ, Schwarz US , Ishizaki T , Narumiya S , Kam Z, Geiger B , Bershadsky AD 2001; Focal contacts as mechanosensors: externally applied local mechanical force induces growth of focal contacts by an mDial-dependent and ROCK-independent mechanism. J Cell Biol. 153: 1175 - 1186

- Ronty M , Taivainen A , Moza M , Kruh GD , Ehler E , Carpen O 2005; Involvement of palladin and alpha-actinin in targeting of the Abl/Arg kinase adaptor ArgBP2 to the actin cytoskeleton. Exp Cell Res. 310: 88- 98

- Rosenberger G, Kutsche K 2006; AlphaPIX and betaPIX and their role in focal adhesion formation. Eur J Cell Biol. 85: 265- 274

- Rottner K, Hall A, Small JV 1999; Interplay between Rac and Rho in the control of substrate contact dynamics. Curr Biol. 9: 640- 648

- Rucci N, DiGiacinto C, Orru L, Millimaggi D, Baron R, Teti A 2005; A novel protein kinase C alpha-dependent signal to ERK1/2 activated by alphaVbeta3 integrin in osteoclasts and in Chinese hamster ovary (CHO) cells. J Cell Sci. 118: 3263- 3275

- Saltel F, Chabadel A, Zhao Y, Lafage-Proust MH, Clezardin P, Jurdic P, Bonnelye E 2006; Transmigration: a new property of mature multinucleated osteoclasts. J Bone Miner Res. 21: 1913- 1923

- Sanjay A, Houghton A, Neff L, DiDomenico E, Bardelay C, Antoine E, Levy J, Gailit J, Bowtell D, Horne WC, Baron R 2001; Cbl associates with Pyk2 and Src to regulate Src kinase activity, alpha(v)beta(3) integrin-mediated signaling, cell adhesion, and osteoclast motility. J Cell Biol. 152: $181-195$

- Schaller MD , Hildebrand JD , Shannon JD, Fox JW , Vines RR , Parsons JT 1994; Autophosphorylation of the focal adhesion kinase, pp125FAK, directs SH2- dependent binding of pp60src. Mol Cell Biol. 14: 1680- 1688

- Schnaeker EM , Ossig R, Ludwig T, Dreier R, Oberleithner H , Wilhelmi M , Schneider SW 2004; Microtubule-dependent matrix metalloproteinase-2/matrix metalloproteinase-9 exocytosis: prerequisite in human melanoma cell invasion. Cancer Res. 64: 8924- 8931

- Schober M , Raghavan S, Nikolova M, Polak L, Pasolli HA, Beggs HE, Reichardt LF, Fuchs E 2007; Focal adhesion kinase modulates tension signaling to control actin and focal adhesion dynamics. J Cell Biol. 176: 667- 680

- Schwarz US , Balaban NQ, Riveline D, Bershadsky A, Geiger B , Safran SA 2002; Calculation of Forces at Focal Adhesions from Elastic Substrate Data: The Effect of Localized Force and the Need for Regularization. Biophysical Journal. 83: 1380- 1394

- Serrels B , Serrels A, Brunton VG, Holt M , McLean GW, Gray CH , Jones GE, Frame MC 2007; Focal adhesion kinase controls actin assembly via a FERM-mediated interaction with the Arp2/3 complex. Nat Cell Biol. 9: 1046- 1056

- Siegel DH, Ashton GH , Penagos HG, Lee JV , Feiler HS , Wilhelmsen KC, South AP , Smith FJ , Prescott AR, Wessagowit V , Oyama N , Akiyama M , Al Aboud D , Al Aboud K , Al Githami A, Al Hawsawi K, Al Ismaily A , Al-Suwaid R , Atherton DJ , Caputo R , Fine JD , Frieden IJ , Fuchs E , Haber RM , Harada T , Kitajima Y , Mallory SB , Ogawa H, Sahin S, Shimizu H, Suga Y, Tadini G, Tsuchiya K, Wiebe CB , Wojnarowska F, Zaghloul AB , Hamada T , Mallipeddi R, Eady RA , McLean WH , McGrath JA , Epstein EH 2003; Loss of kindlin-1, a human homolog of the Caenorhabditis elegans actin-extracellular-matrix linker protein UNC-112, causes Kindler syndrome. Am J Hum Genet. 73: 174- 187

- Soltoff SP , Cantley LC 1996; p120cbl is a cytosolic adapter protein that associates with phosphoinositide 3-kinase in response to epidermal growth factor in PC12 and other cells. J Biol Chem. 271: 563- 567

- Soriano P, Montgomery C, Geske R, Bradley A 1991; Targeted disruption of the c-src proto-oncogene leads to osteopetrosis in mice. Cell. 64: 693- 702

- Stofega MR, Sanders LC, Gardiner EM, Bokoch GM 2004; Constitutive p21- activated kinase (PAK) activation in breast cancer cells as a result of mislocalization of PAK to focal adhesions. Mol Biol Cell. 15: 2965- 2977

- Tadokoro S, Shattil SJ , Eto K, Tai V , Liddington RC, de Pereda JM , Ginsberg MH , Calderwood DA 2003; Talin binding to integrin beta tails: a final common step in integrin activation. Science. 302: 103- 106

- Tang DD , Gunst SJ 2004; The small GTPase Cdc42 regulates actin polymerization and tension development during contractile stimulation of smooth muscle. J Biol Chem. 279: 51722- 51728

- Tang DD , Turner CE , Gunst SJ 2003; Expression of non-phosphorylatable paxillin mutants in canine tracheal smooth muscle inhibits tension development. J Physiol. 553: 21 $-35$ 
- Tarone G, Cirillo D, Giancotti FG, Comoglio PM, Marchisio PC 1985; Rous sarcoma virus-transformed fibroblasts adhere primarily at discrete protrusions of the ventral membrane called podosomes. Exp Cell Res. 159: 141- 157

- Tehrani S , Faccio R, Chandrasekar I, Ross FP, Cooper JA 2006; Cortactin has an essential and specific role in osteoclast actin assembly. Mol Biol Cell. 17: 2882- 2895

- Tehrani S , Tomasevic N, Weed S, Sakowicz R, Cooper JA 2007; Src phosphorylation of cortactin enhances actin assembly. Proc Natl Acad Sci U S A. 104: 11933- 11938

- Turner CE , Brown MC, Perrotta JA, Riedy MC, Nikolopoulos SN , McDonald AR, Bagrodia S, Thomas S , Leventhal PS 1999; Paxillin LD4 motif binds PAK and PIX through a novel 95-kD ankyrin repeat, ARF-GAP protein: A role in cytoskeletal remodeling. J Cell Biol. 145: 851- 863

- Vicente-Manzanares M , Webb DJ , Horwitz AR 2005; Cell migration at a glance. J Cell Sci. 118: 4917- 4919

- Wang Q, Xie Y, Du QS , Wu XJ , Feng X, Mei L, McDonald JM , Xiong WC 2003; Regulation of the formation of osteoclastic actin rings by proline-rich tyrosine kinase 2 interacting with gelsolin. J Cell Biol. 160: 565- 575

- Watanabe N , Kato T , Fujita A , Ishizaki T , Narumiya S 1999; Cooperation between mDia and ROCK in Rho-induced actin reorganization. Nat Cell Biol. 1: 136- 143

- Webb BA, Eves R, Crawley SW, Zhou S, Cote GP , Mak AS 2005; PAK1 induces podosome formation in A7r5 vascular smooth muscle cells in a PAK-interacting exchange factor-dependent manner. Am J Physiol Cell Physiol. 289: C898- 907

- Webb BA , Jia L , Eves R, Mak AS 2007; Dissecting the functional domain requirements of cortactin in invadopodia formation. Eur J Cell Biol. 86: 189- 206

- Webb DJ , Donais K, Whitmore LA, Thomas SM , Turner CE , Parsons JT , Horwitz AF 2004; FAK-Src signalling through paxillin, ERK and MLCK regulates adhesion disassembly. Nat Cell Biol. 6: 154- 161

- Yamaguchi H, Lorenz M , Kempiak S, Sarmiento C, Coniglio S, Symons M, Segall J, Eddy R, Miki H, Takenawa T , Condeelis J 2005; Molecular mechanisms of invadopodium formation: the role of the N-WASP-Arp2/3 complex pathway and cofilin. J Cell Biol. 168: 441- 452

- Yan B , Calderwood DA, Yaspan B , Ginsberg MH 2001; Calpain cleavage promotes talin binding to the beta 3 integrin cytoplasmic domain. J Biol Chem. 276: 2816428170

- Yu DH , Qu CK , Henegariu O, Lu X , Feng GS 1998; Protein-tyrosine phosphatase Shp-2 regulates cell spreading, migration, and focal adhesion. J Biol Chem. 273: 2112521131

- Zaidel-Bar R , Itzkovitz S , Ma'ayan A , Iyengar R , Geiger B 2007; Functional atlas of the integrin adhesome. Nat Cell Biol. 9: 858- 867

- Zamir E , Geiger B 2001; Molecular complexity and dynamics of cell-matrix adhesions. J Cell Sci. 114: 3583- 3590

- Zamir E , Katz BZ, Aota S , Yamada KM , Geiger B , Kam Z 1999; Molecular diversity of cell-matrix adhesions. J Cell Sci. 112: (Pt 11) 1655- 1669

- Zhang W, Wu Y, Du L, Tang DD, Gunst SJ 2005; Activation of the Arp2/3 complex by N-WASp is required for actin polymerization and contraction in smooth muscle. Am J Physiol Cell Physiol. 288: C1145- 1160

\section{Figure 1}

Architecture and composition of adhesive structures

A. Tangential adhesive structures. MEF cells spread on a fibronectin matrix were stained to visualize either $\beta 1$ integrin containing focal adhesion (Fa) and focal complex (Fx) or fibronectin to localize fibrillar adhesion (Fb). B. Schema representing Fa organization. IAP: Integrin Associated Protein (CD47) C. Perpendicular adhesive structures. RSV-transformed BHK cells were transfected with cortactin-DsRed and stained for vinculin and paxillin phosphorylated on Y118 (P-Paxillin). Confocal analysis displays a rosette of PTA (Podosome-type adhesion). One structural unit (PTA) is presented on zoom pictures and is made by one core surrounded by adhesion proteins. D. Schema representing the architecture of PTA.
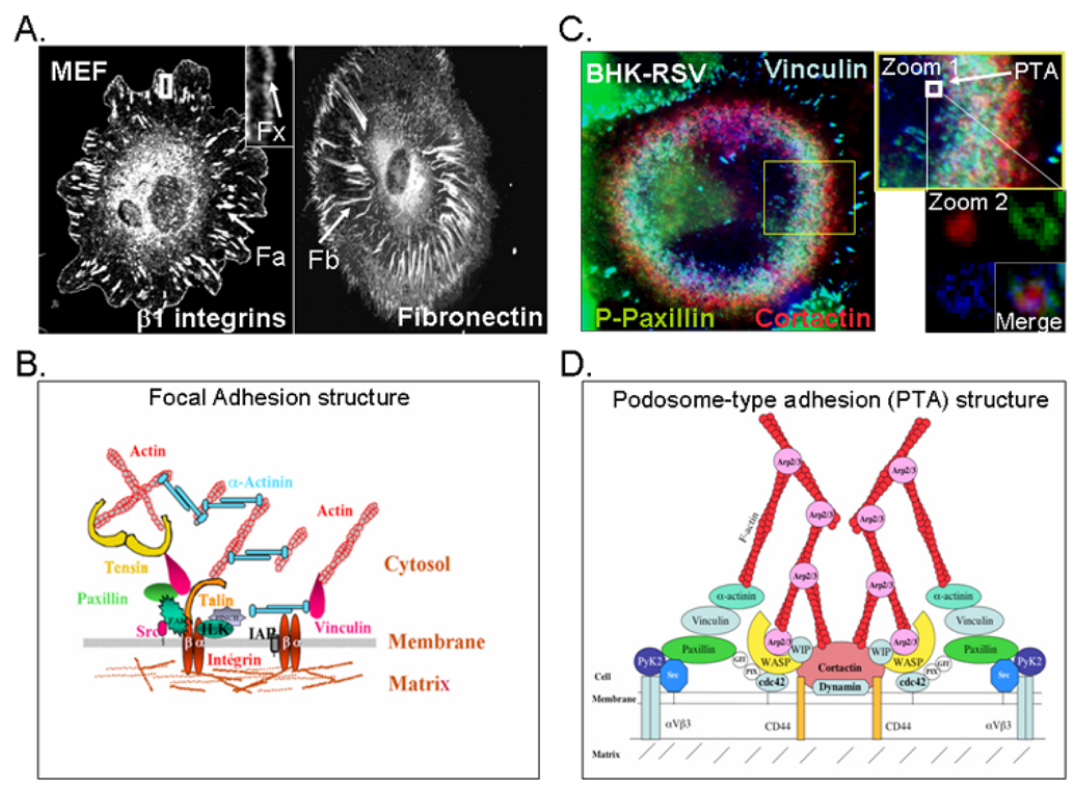
Figure 2

Dynamics of adhesion structures

A. Turnover of Fa. VASP-GFP expressing MEF cells spread on a fibronectin matrix were monitored over a 6 hours period. At the birth of a nascent $\mathrm{Fa}$ (white arrow), the clustering of integrins and the recruitment of focal adhesion proteins induce an increase of GFP-VASP fluorescence until it reaches a brief plateau denoting the mature adhesion which is immediately follows by the decrease of GFP fluorescence and the dissociation of proteins leading to the disassembly of adhesion site. B. Turnover of PTA. Cortactin-GFP transfected BHK-RSV cells were treated with sodium orthovanadate $5 \mathrm{mM}$ to allow rosette expansion and observed over a 130 min period. Ring expansion is allowed by new PTA formation at the rosette periphery (white circle) and disassembly of PTA at the rosette center.

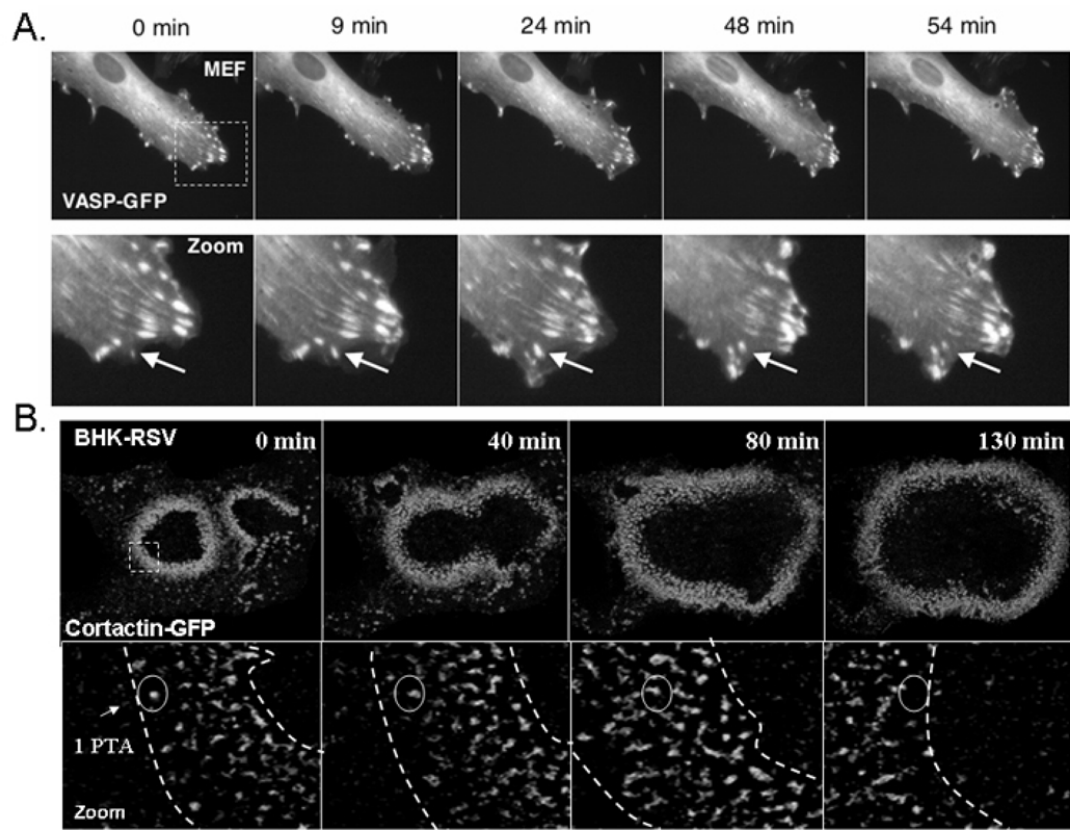


Table 1

Comparison of PTA and Fa associated proteins

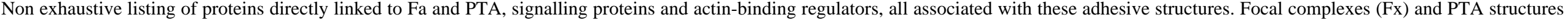

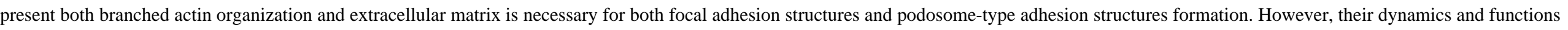
are quite distinct.

\begin{tabular}{|c|c|c|c|}
\hline \multirow[b]{3}{*}{ Composition } & \multicolumn{3}{|c|}{ Adhesion structures } \\
\hline & \multirow[b]{2}{*}{ Focal adhesion (Fa, Fx, Fb) } & \multicolumn{2}{|c|}{ Podosome type Adhesion (PTA) } \\
\hline & & Podosome & Invadopodia \\
\hline$\overline{\text { Talin }}$ & $+(\mathrm{Fa}, \mathrm{Fx})$ & + & + \\
\hline Vinculin & $+(\mathrm{Fa}, \mathrm{Fx})$ & + & + \\
\hline Paxillin & $+(\mathrm{Fa}, \mathrm{Fx})$ & + & + \\
\hline a-actinin & $+(\mathrm{Fa})$ & + & + \\
\hline Zyxin & $+(\mathrm{Fa})$ & $?$ & $?$ \\
\hline Integrins & + & + & + \\
\hline $\mathrm{CD} 44$ & $?$ & + & + \\
\hline Kindlin & + & + & $?$ \\
\hline Src & + & + & + \\
\hline FAK/Pyk2 & + & + & + \\
\hline PI3K & + & + & + \\
\hline PAK & + & + & + \\
\hline $\mathrm{Cdc} 42$ & - & + & + \\
\hline Rac1 & - & + & + \\
\hline P130cas & + & + & + \\
\hline P120RasGAP & + & + & + \\
\hline P190RhoGAP & + & + & + \\
\hline $\mathrm{Cbl}$ & + & + & + \\
\hline Actin organisation & bundle $(\mathrm{Fa}, \mathrm{Fb})+$ branched $(\mathrm{Fx})$ & bundle $($ cloud $)+$ branched (core) & $?$ \\
\hline WASP/N-WASP & - & + & + \\
\hline WIP & - & + & + \\
\hline Arp2/3 complex & - & + & + \\
\hline Cortactin & - & + & + \\
\hline Dynamin-2 & $?$ & + & + \\
\hline VASP & + & + & + \\
\hline Fimbrin & + & + & + \\
\hline Cofilin & + & + & + \\
\hline Gelsolin & + & + & + \\
\hline
\end{tabular}




\section{ECM-dependent formation}

\section{Dynamics}

Individual

$+$

Collective

migration

Rosette formation/expansion

Rosette formation/expansion (Src-BHK cells)

Functions

Adhesion

Migration

ECM remodeling (FN fibrillogenesis)

ECM degradation

+++
+++
$+++(\mathrm{Fb})$
$+/-$

